\title{
Cell Proliferation-Associated Expression of a Recently Evolved Isozyme of Triosephosphate Isomerase
}

\author{
R. S. Decker ${ }^{1,2}$ and H. W. Mohrenweiser ${ }^{1}$ \\ Received 30 May 1984-Final 12 Oct. 1984
}

\begin{abstract}
An electrophoretically unique, thermolabile isozyme of triosephosphate isomerase (TPI; EC 5.3.1.1) accounts for 10-30\% of the enzymatic activity in a range of mitotically active human cells and tissues. This type 2 form (subunit) of human TPI appears in two isozymes, an anodally migrating, relative to the constitutive TPI-1/1 homodimer, TPI-2/2 homodimer and the TPI-1/2 heterodimer with an intermediate mobility. Human cell types expressing the induced isozyme, which is the product of the same structural locus as the constitutive isozyme, include mitogen-stimulated lymphocytes, virally transformed B-lymphoblastoid cells, leukemia-derived T-lymphoblastoid cells, HeLa cells, both normal and transformed fibroblasts, and placental tissue. Extracts of nondividing or terminally differentiated human cells/tissues, such as erythrocytes, striated muscle, peripheral lymphocytes, and platelets, contain high levels of the constitutive TPI-1/1 isozyme but little or undetectable levels of the TPI-I/2 or TPI-2/2 isozyme. The cell division-associated TPI-1/2 and $-2 / 2$ isozymes are distinct in electrophoretic mobility from the deamidated forms of the constitutive isozyme. Extracts of dividing gorilla fibroblasts display an isozyme pattern identical to that of proliferating human cells, but various proliferating cells derived from the African green monkey, rabbit, and chicken express only the constitutive isozyme. Thus, expression of the cell division-associated isozyme of TPI is restricted to the hominoids, suggesting a recently evolved modification mechanism which is specifically activated in proliferating cells.
\end{abstract}

Financial support was derived from Contract EY-77-C-02-2828 from the Department of Energy and Training Grant 5-T32-GM07544 from the National Institutes of Health.

' Department of Human Genetics, University of Michigan Medical School, Ann Arbor, Michigan 48109-0010.

${ }^{2}$ Present address: Department of Biological Chemistry, Harvard Medical School, Boston, Massachusetts 02115. 
KEY WORDS: triosephosphate isomerase; hominoid; cell division isozyme.

\section{INTRODUCTION}

Multiple isozymes, different molecular forms of an enzyme as described by Markert (1974), are observed for many enzymes following electrophoresis of cell and tissue extracts. These multiple forms include allelic variants, gene products of duplicated structural loci, or electromorphs which result from spontaneous aging of the primary isozyme (Harris, 1980). Isozymic forms may also be generated by specific posttranslational events such as proteolytic cleavage and covalent ligand binding (see Wold, 1981) and noncovalent binding of cofactors (Dreyfus et al., 1978). In addition to posttranslational events, examples of multiple isozymes from a single structural locus have now been shown to be produced by (1) gene reorganization (Early et al., 1980; Nasmyth and Tatchell, 1980) and (2) differential transcript processing (Crabtree and Kant, 1982; Marie et al., 1982; Young et al., 1981; Levin et al., 1982; Capetanaki et al., 1983; Schwarzbauer et al., 1983; Nabeshima et al., 1984).

Triosephosphate isomerase (TPI; EC 5.3.3.1), a dimeric molecule of identical subunits of $26,000-27,000$ daltons is one enzyme where multiple isozyme forms are observed following electrophoresis of extracts from tissues from a range of species (Scopes, 1968; Snapka et al., 1974). Several mechanisms are known to account for the electrophoretic multiplicity of human TPI. A series of anodally migrating isozymes of TPI, which are constitutively expressed in all human cells, has been shown to originate via sequential deamidations of asparagine residues at positions 15 and 71 (Gracy and Yuan, 1980). Consistent with this observation is the presence of these isozymes in rabbit TPI (Corran and Waley, 1975) but not in the chicken enzyme (Putnam et al., 1972), where a lysine residue occupies position 71 (Banner et al., 1975). Allelic variation has also been reported, but the frequency of mobility variants, at least in humans, is very low (Harris et al., 1974; Neel et al., 1980a,b).

An additional, thermolabile, anodally migrating form of the human enzyme has been observed in mitogen-stimulated lymphocytes (Decker and Mohrenweiser, 1981; Kester and Gracy, 1975; Rogers et al., 1980). This isozyme has structural and kinetic properties which are very similar to those observed for the constitutive isozyme (Kester et al., 1977; Yuan et al., 1970). Dreyfus and co-workers have also identified electrophoretically distinct isozymes in human fibroblasts (Rubinson et al., 1971) and have reported that these isozymes are detectable only in fibroblasts derived from hominoid species (Rubinson et al., 1973). Although these isozymes were initially proposed to be the product of a second structural locus (Kester et al., 1977; 
Yuan et al., 1979), subsequent genetic studies have demonstrated that the constitutive isozyme (TPI-1 subunit) and the thermolabile, cell divisionassociated isozyme (TPI-2 subunit) are actually products of the same structural locus (Decker and Mohrenweiser, 1981).

The present study expands our previous work on the expression and identity of the TPI-2 isozyme. The examination of a series of normal and transformed cell lines of human and nonhuman origin defines the range of TPI-2 expression and correlates TPI-2 expression with the general state of cellular proliferation. The restricted pattern of expression found for the TPI-2 isozyme contrasts with the wide distribution, both within and between species, which is observed for the TPI-1 isozyme and its associated deamidated forms. An increase in electrophoretic resolution has allowed us to clearly establish the nonidentity of the TPI- $1 / 2$ isozyme with the deamidation products of the TPI- $1 / 1$ isozyme and to demonstrate the presence of the rapidly migrating TPI-2/2 isozyme in stimulated lymphocytes and placenta.

\section{MATERIALS AND METHODS}

The electrophoretic techniques were as described by Decker and Mohrenweiser (1981) except that the polyacrylamide gel dimensions were $16.0 \times$ $18.0 \times 0.15 \mathrm{~cm}$. TPI activity was detected using $6 \mathrm{~mm}$ dihydroxyacetone phosphate-lithium (Sigma, St. Louis, Mo.) as substrate. Cellulose acetate strips (Gelman, Ann Arbor, Mich.) were soaked in staining solution and overlayed on the gel, which was incubated at $37^{\circ} \mathrm{C}$. The reaction was stopped by fixing the strips in $7 \%$ acetic acid, usually after $15 \mathrm{~min}$; 5 - and 30 -min incubation times were also used to monitor the intensity of the prominent bands and to facilitate the search for additional weakly staining bands.

The B-lymphoblastoid cell line (UM-121) was derived from a heterozygous individual with the TPI-N/Manchester genotype (Asakawa and Mohrenweiser, 1982; Decker and Mohrenweiser, 1981) and was established via the viral transformation procedure of Yamamota and zurHansen (1979). The human B-lymphoblastoid cell line, UM-61, was described by Choi and Bloom (1970). Four additional, virally transformed, human B-lymphoblastoid cell lines (KC, ES, IV, and LP), as well as two human B-lymphoblastoid cell lines (MGL-8 and GM-130) and two leukemia-derived human T-lymphoblastoid cell lines (MOLT-4 and CEM-CCRF), were supplied by Dr. P. Daddona, Department of Internal Medicine, University of Michigan (UM). The normal human fibroblast cells, DA-S and GM-41, were obtained from Dr. C. W. Castor (Department of Internal Medicine, UM) and Dr. J. Thoene (Department of Pediatrics, UM). The chemically transformed human fibroblasts, HUT-1-11, were from Dr. T. Featherstone and the HeLa derivative (TK ${ }^{-}$, BU-25) was from Dr. B. Wu, both of the Department of Human Genetics, 
UM. The normal gorilla fibroblasts (TCH 3228) were from Dr. T. C. Hsu of the Department of Cell Biology, M. D. Anderson Hospital and Tumor Institute, Houston, Tex. The transformed African green monkey (Ceropithecus aethiops) kidney cell line, Vero, and the primary rabbit kidney cells were from Dr. R. Sandri-Goldin of the Department of Human Genetics, UM. The primary human and rabbit lymphocytes were isolated and cultured as previously described by Decker and Mohrenweiser (1981). Platelets were isolated by differential centrifugation (Long et al., 1985). All lysates of cultured cells as well as extracts of placental and muscle tissue were prepared as described by Decker and Mohrenweiser (1981).

\section{RESULTS}

The electrophoretic patterns for TPI activity from human erythrocytes, peripheral lymphocytes, and mitogen-stimulated lymphocytes, from both a normal (TPI-N/N) and a heterozygous variant (TPI-N/Manchester) TPI phenotype individual, are shown in Fig. 1. The erythrocyte isozyme patterns for the individual with the normal phenotype (lane 6) and the heterozygous TPI-N/Manchester individual (lane 5) are as previously described (Asakawa and Mohrenweiser, 1982). The difference between the pattern in erythrocytes and that in lymphocytes (lanes 3 and 4) presumably reflects the aging process of erythrocyte TPI via deamidation of the primary isozyme (Gracy and Yuan, 1980). The TPI-N/Manchester pattern is consistent with the dimeric subunit structure of this enzyme.

The TPI isozyme pattern in extracts of mitogen-stimulated lymphocytes for an individual with a normal phenotype (lane 2 ) is characterized by the appearance of additional, anodally migrating bands as described previously (Decker and Mohrenweiser, 1981). An additional isozyme band, with a mobility approximately similar to that of the isozyme having undergone four deamidations (Gracy and Yuan, 1980) and termed TPI-A in recent reports (Kester and Gracy 1974; Kester et al., 1977; Decker and Mohrenweiser, 1981), is observed in the stimulated lymphocytes (lane 2). Another even more anodally migrating isozyme band becomes detectable when the level of enzymatic activity applied to the gel is increased or the staining time is lengthened.

The variant pattern of mitogen-induced TPI isozymes, including the rapidly migrating $2 \mathrm{~N} 2 \mathrm{~N}$ and $2 \mathrm{~N} 2 \mathrm{M}$ allozymes, can be seen in lane 1. Equal amounts of enzyme activity were electrophoresed in samples 1 through 4 to allow a comparison of the relative staining intensity of the individual isozymes. The single structural TPI gene model is supported by (1) a lessened staining intensity in the $2 \mathrm{~N} 2 \mathrm{~N}$ position and (2) the appearance of allozymes unique to the variant phenotype in the $2 \mathrm{~N} 2 \mathrm{M}$ and $1 \mathrm{M} 2 \mathrm{M}$ positions. Some of 


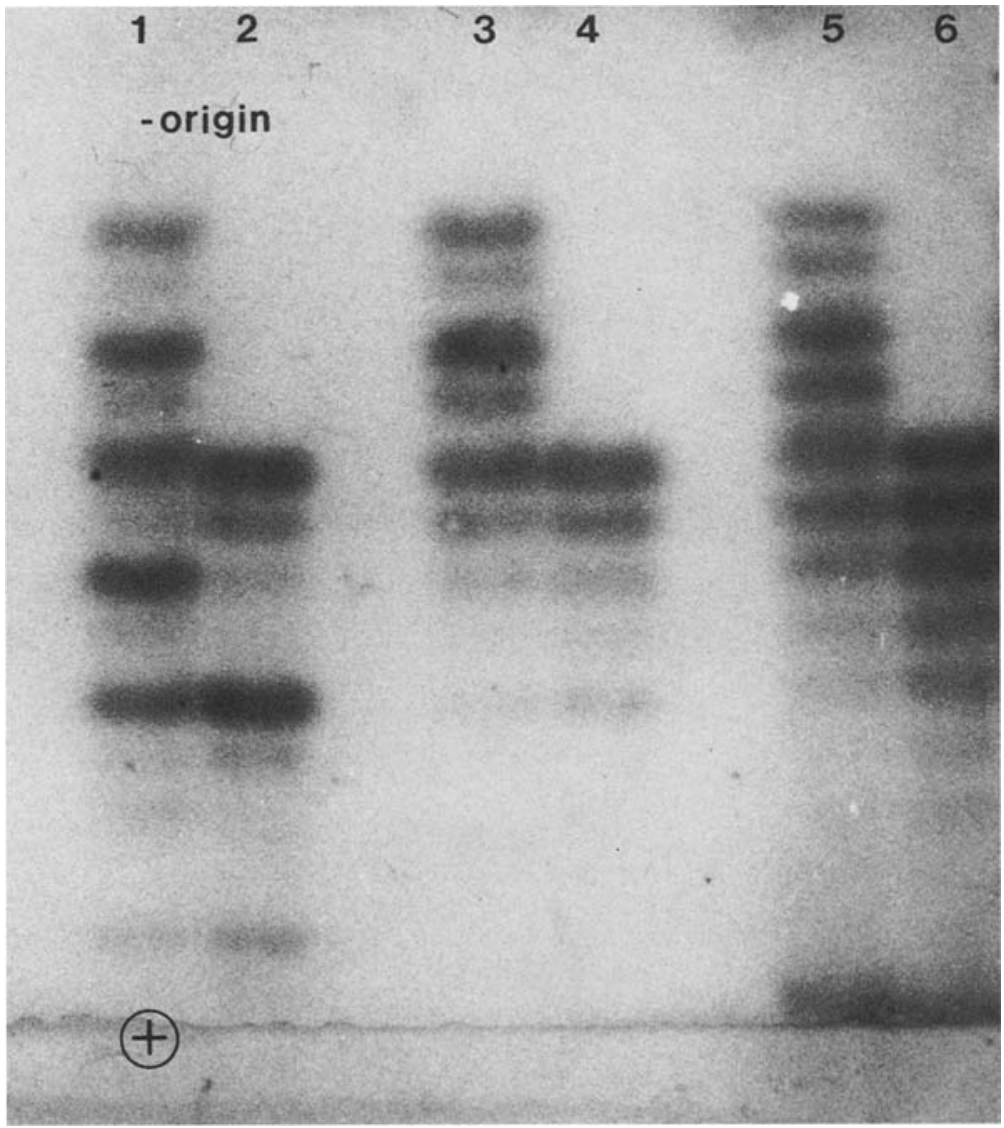

Fig. 1. Electrophoretic analysis of human triosephosphate isomerase isozymes. The samples in lanes 1, 3, and 5 are from a heterozygous individual with a TPI-N/ Manchester phenotype, while the samples in lanes 2, 4, and 6 are from an individual with a TPI-N/N phenotype. Lanes 1 and 2 are lymphoblasts after $75 \mathrm{hr}$ of phytohemagglutinin stimulation, lanes 3 and 4 are peripheral lymphocytes, and lanes 5 and 6 are erythrocytes. Enzymatic activity was detected as described in Materials and Methods.

the dimeric allozymes which contain a $2 \mathrm{M}$ subunit are predicted to comigrate with isozymes composed of two normal subunits (see Fig. 2). In the case of $1 \mathrm{~N} 1 \mathrm{~N}$ and $1 \mathrm{M} 2 \mathrm{M}$, resolution of these allozymes was achieved by extending the migration distance (Decker and Mohrenweiser, 1981).

A schematic of the electrophoretic patterns is presented in Fig. 2. The constitutive TPI subunits are designated " 1 " and the thermolabile, mitogeninduced TPI subunits are designated "2." The " $N$ " and " $M$ " nomenclature represents the normal and Manchester variant subunits, respectively. As seen 


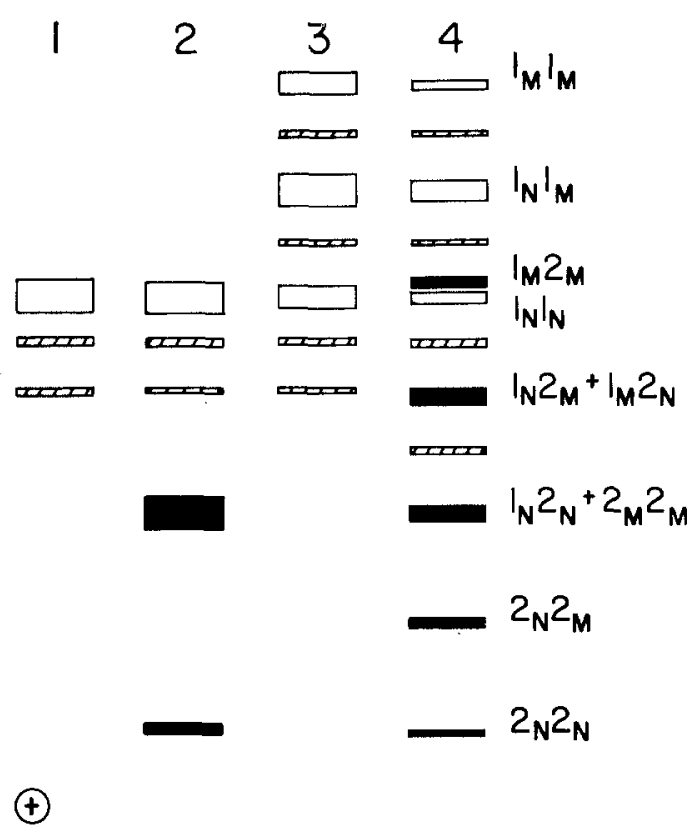

Fig. 2. Schematic representation of triosephosphate isomerase isozymes from Fig. 1. "l" indicates TPI-1 subunits and "2" indicates TPI-2 subunits, while " $N$ " indicates normal subunits and " $\mathrm{M}$ " indicates Manchester variant subunits. ( $\square$ ) Constitutive isozyme; ( $\square$ ) cell division-associated isozymes; ( שים ) deamidated forms of constitutive isozymes; (Note: lanes 1 and 4 are reversed from Figure 1).

in lane 2 of Fig. 2, the pattern is that expected for a dimeric enzyme formed from two types of subunits. The present designation of the TPI-A or $-1 / 2$ isozyme as a heterodimer, in contrast to a homodimeric molecule (Decker and Mohrenweiser, 1981), results from the identification of the anodal $2 / 2$ isozyme (Figs. 1 and 2). Additionally, the results of isoelectricfocusing experiments of the purified isozymes, conducted in the presence of $8 \mathrm{M}$ urea, indicate a homodimeric subunit structure for TPI $1 / 1$, while the isozyme designated TPI $1 / 2$ is composed of two types of subunits, one being the TPI 1 subunit, (Decker and Mohrenweiser, 1983; Decker and Mohrenweiser, in preparation). The genetic origins of the TPI-1 and -2 subunits are still interpreted as a single structural locus when viewed in terms of a TPI-1/1, $-1 / 2$, and $-2 / 2$ isozyme pattern.

The TPI- $1 / 2$ heterodimer was detected in a wide range of cultured human cells. It was detected in nine different transformed human B- 
lymphoblastoid lines and in two leukemia-derived human T-cell lines. TPI$1 / 2$ was also present in the extracts of both normal and transformed human fibroblast cell lines. Thus, the expression of the TPI- 2 subunit appears to be a general property of cells active in cell division rather than an association with specific cell types or tissues.

The electrophoretic profile of the TPI isozymes was also examined in several differentiated human tissues and cells (Fig. 3). Similar patterns were observed in hemolysate (lane 1) and striated muscle extract (lanes 2 and 9), with some $8-10$ bands of TPI activity being detectable. The activity bands immediately anodal to the constitutive TPI-1 isozyme are designated TPI-1', $-1^{\prime \prime}$, etc. [corresponding to bands b-e of Peters et al. (1973)], and have been demonstrated to be the products of spontaneous deamidation (Gracy and Yuan, 1980). Peripheral lymphocytes (lane 7) and platelets (lane 8) exhibit a pattern of a major band, which is identical in mobility to the major band in muscle and erythrocyte, but only a weak staining intensity is observed in the position of the TPI-1' through -1 " isozymes. The isozyme pattern of placenta is similar to that of stimulated lymphocytes; the TPI- $1 / 1$ and TPI- $1 / 2$ bands are the most intensely staining. Also, the proposed TPI-2/2 homodimer is clearly visible in placental extract (lane 10). In experiments not presented here, the TPI-2/2 isozyme is also observed in the lymphoblastoid cells when large amounts of extracts are electrophoresed.

A comparison of the TPI isozymes arising via deamidation in placentae and muscle shows identical comigration in both samples; however, the TPI- $1 " / 1$ " band, quite pronounced in muscle extract (lane 11) and barely apparent in placental tissue, clearly has a different rate of electrophoretic migration than the TPI-1/2 isozyme of placentas (lane 10). The high amounts of TPI in striated muscle allow the visualization of a large number of human TPI isozymes including very low levels of the TPI-1/2 isozyme, which again confirms that the TPI-1/2 and TPI-1"/1" isozymes are distinct and separate isozymes. The electrophoretic profile of the TPI isozymes from erythrocytes, stimulated lymphocytes, and muscle is presented schematically in Fig. 4.

During the course of these studies we sought to reexamine the phylogenetic range of expression of the TPI type 2 subunit. An earlier observation by Dreyfus and coworkers (1973) indicated that their "intermediate" and "very fast" isozymes were not found in primary fibroblast cultures of nonhominoid primates or lower mammals.

As seen in Fig. 5, fibroblasts derived from the gorilla (lane 3) have isozymes with mobilities similar to those of both the TPI-1/1 and the TPI-1/2 isozymes from transformed human lymphoblasts (lane 2). A band comigrating with TPI-2/2 is also observed but only after prolonged staining. In contrast, extracts of rapidly dividing African green monkey kidney (lane 4) exhibit only a single prominent band of TPI activity which comigrates with 


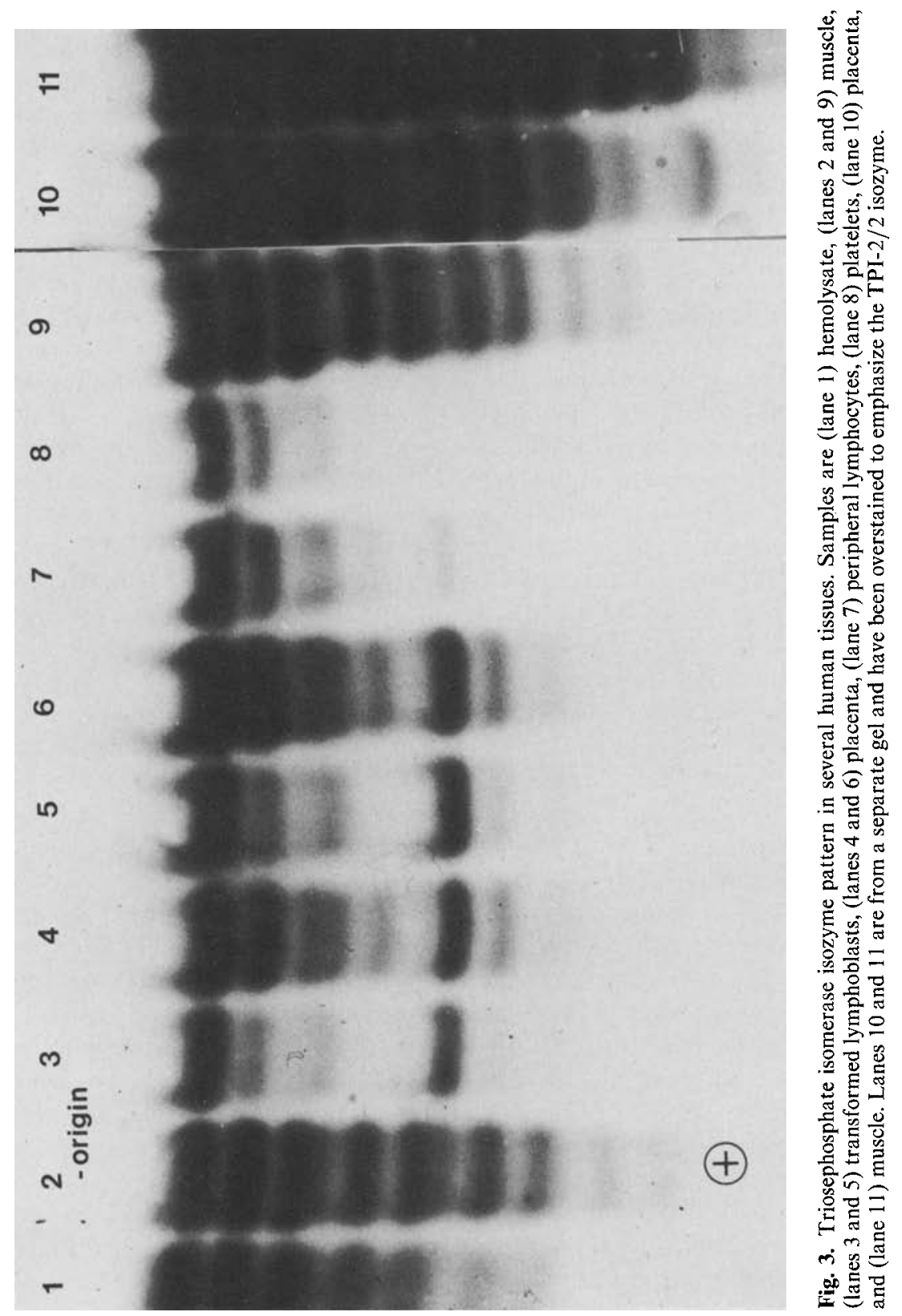




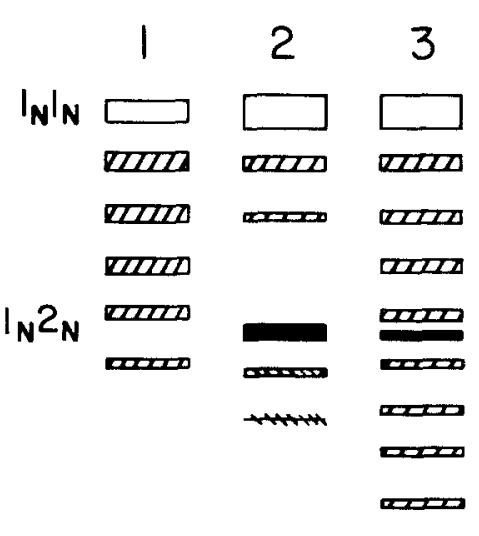

Fig. 4. Schematic representation of TPI isozymes from Fig. 3. Lane 1 is erythrocytes, lane 2 is transformed lymphoblasts, and lane 3 is muscle extract.

the TPI- $1 / 1$ isozyme of human and gorilla and two minor bands which are presumably the first two deamidation bands of TPI-1/1. The pattern observed with extracts of mitogen-stimulated rabbit lymphocytes (lanes 6 and 8) and cultured primary rabbit kidney cells (lane 7 ) indicates a single major isozyme and minor associated bands, presumably arising via spontaneous deamidation. All of these cells had growth characteristics similar to those of the comparable human cell, thus differences are not a reflection of differences in culture conditions or growth rates. The pattern in both of the rabbit cell types is identical to that detected in unstimulated rabbit lymphocytes (lane 5). It should be noted that the TPI isolated from rabbit and human differ by only some 12 residues and both enzymes contain the labile asparagine residues (Oray et al., 1983). In further studies, only a single band of enzyme activity was detected in chicken B- and T-lymphoblast cells (data not shown). The lack of deamidation products is consistent with the replacement of lysine for asparagine in the 15th position of chicken TPI and the model of sequential deamidation proposed by Yuan et al. (1983). Thus, in none of the extracts of rapidly dividing cells from the green monkey, rabbit, or chicken is an isozyme found which is analogous to the human proliferation-specific, TPI- $1 / 2$ isozyme. This is in contrast to the observations from the proliferating human and gorilla cells which contain high levels of the TPI-1/2 isozyme. The phylogenetic expression data are summarized in Table I.

\section{DISCUSSION}

The thermolabile TPI- $1 / 2$ isozyme accounts for approximately $50 \%$ of the enzyme activity in human lymphocyte cells after $72 \mathrm{hr}$ of mitogen stimulation 


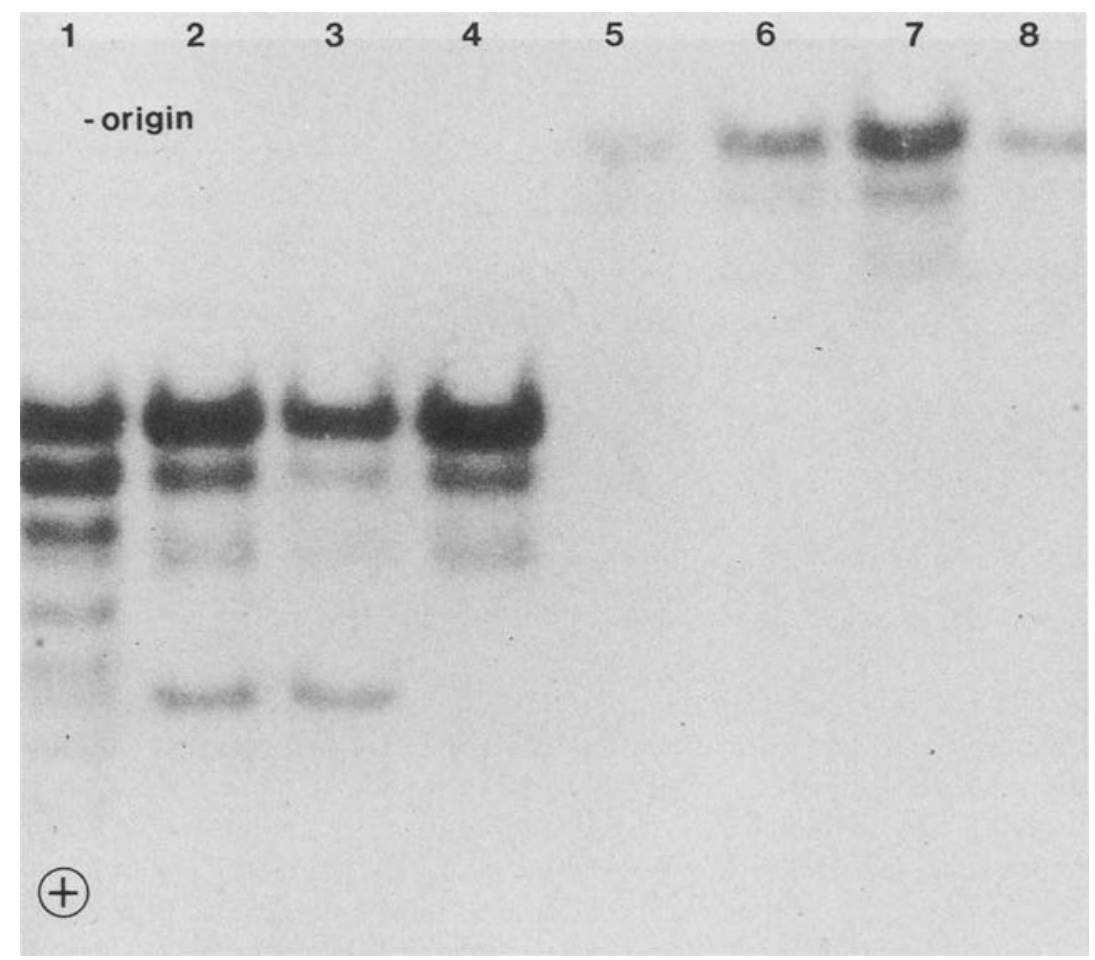

Fig. 5. Electrophoretic analysis of triosephosphate isomerase isozymes in several species. Samples are (lane 1) human muscle, (lane 2) transformed human lymphoblasts, (lane 3) gorilla fibroblasts, (lane 4) African green monkey kidney cells, (lane 5) rabbit peripheral lymphocytes, (lanes 6 and 8 ) rabbit primary lymphoblasts, and (lane 7) rabbit primary kidney cells.

(Decker and Mohrenweiser, 1981) and approximately 20\% of the total TPI activity in several asynchronously dividing, virally transformed lymphoblastoid cell lines (Decker and Mohrenweiser, in preparation). The TPI-1/2 isozyme is detectable in a wide range of cultured human cells, including normal as well as chemically and virally immortalized cells. TPI- $1 / 2$ is also present in placental extracts but is absent in erythrocytes and platelets and only barely detectable in extracts of striated muscle, which is consistent with a relationship of TPI-1/2 expression and cell division. Thus, this isozyme does not appear to be associated with specific differentiation processes but rather is the result of a process which occurs during cell growth and division.

In contrast to the general nature of TPI- $1 / 2$ expression in various proliferating human cells, the expression of TPI- $1 / 2$ is restricted to proliferating cells derived only from the hominoid species. The detection of the TPI- $1 / 2$ isozyme in cultured cells from gorilla and the complete absence of a 
Table I. Qualitative TPI Isozyme Analysis of Cells in Culture ${ }^{a}$

\begin{tabular}{lccc}
\hline \multicolumn{1}{c}{ Cell type } & \multicolumn{3}{c}{ Isozymic form } \\
\cline { 2 - 4 } & TPI-1/1 & TPI-1'/1 & TPI-1/2 \\
\hline Human primary lymphoblasts $(N-2)$ & + & + & + \\
Human B-cell lymphoblasts, transformed & & & \\
$\quad(N=9)$ & + & + & + \\
Human T-cell lymphoblasts, leukemia de- & + & + & + \\
$\quad$ rived $(N=2)$ & + & + & + \\
Human fibroblast, normal $(N-2)$ & + & + & + \\
Human fibroblast, transformed & + & + & + \\
Human carcinoma (HeLa) & + & + & + \\
Gorilla fibroblast, normal & + & + & - \\
African green monkey kidney, transformed & + & + & - \\
Rabbit kidney, primary & + & + & - \\
Rabbit lymphoblast, primary & + & - & - \\
Chicken B-cell lymphoblasts & + & - & - \\
Chicken T-cell lymphoblasts & + & & + \\
\hline
\end{tabular}

${ }^{a}(+)$ Present; $(-)$ absent. TPI- $1 / 1$ is the constitutive isozyme, TPI $-1^{\prime} / 1$ is the first deamidation product of the constitutive isozyme, and TPI- $1 / 2$ is the heterodimer isozyme composed of one constitutive and one cell division-associated subunit.

TPI-1/2-like isozyme in transformed African green monkey cells and in two types of primary rabbit-cell cultures are in complete agreement with the previous observations (Rubinson et al., 1972). These workers found an analogous TPI isozyme in fibroblast explant cultures of various hominoid species but not in fibroblasts of lower primates or other mammals. The phylogenetic restriction of TPI- $1 / 2$ is in contrast to the situations described for other tissue or cell type-specific isozymes. For example, pyruvate kinase undergoes a tissue-specific modification in mice and rats, as well as humans (Marie et al., 1981; Sakeki, 1982a,b), and placental alkaline phosphatase appears to have a diverse and complex pattern of phylogenetic expression within lower and higher primates (Goldstein et al., 1982).

In the present paper, we have introduced a new isozyme nomenclature for human TPI. The necessity for a new nomenclature is based on two findings. First, we have identified a band of TPI activity in stimulated lymphocytes, placenta, and concentrated lymphoblastoid extracts which migrates in a position identical to that predicted for a mitogen-induced TPI-2/2 homodimer. However, Kester et al. (1977) found no evidence for such an isozyme and described only a single new isozyme (TPI-A) in proliferating lymphocytes and fibroblast cultures. Our results demonstrate that at least low levels of the more anodal TPI-2/2 isozyme are present in stimulated lymphocytes, placenta, and long-term lymphoblastoid cells. An examination of the isozyme pattern in both stimulated lymphocytes and long-term B-lymphoblastoid cells, which 
were obtained, or derived, from an individual with the Manchester variant phenotype, fully supports our previous model for a single structural locus encoding both TPI- 1 and TPI-2. The levels of the TPI-2/2 isozyme are low in all cells and tissues where it is present. The non-steady-state conditions of 72-hr mitogen-stimulated primary lymphocytes make it difficult to predict dimeric isozyme ratios for randomly assorting type 1 and type 2 subunits. However, the long-term lymphoblastoid cultures provide a convenient steadystate system. Heat denaturation assays of the UM61 line indicate a 4:1 ratio of TPI-1/1:TPI- $1 / 2+2 / 2$. Random assortment of types 1 and 2 subunits would thus predict on $81: 18: 1$ isozyme ratio for the $1 / 1: 1 / 2: 2 / 2$ dimers; $1 \%$ levels for TPI- $2 / 2$ in these cells are consistent with that observed with isozyme activity staining. Second, in experiments to be published elsewhere, purified isozymes were subjected to isoelectric focusing in the presence of $8 \mathrm{M}$ urea. The results indicate that the isozyme which we and others (Decker and Mohrenweiser, 1981; Kester et al., 1976) had previously designated the TPI-A homodimer is in fact composed of a constitutive subunit (type 1) and a cell division-associated TPI subunit, which we now designate type 2.

The absence of the TPI- $1 / 2$ isozyme from the cultured green monkey and rabbit cells supports our conclusion that the TPI- 2 subunit does not arise due to spontaneous deamidation. Both the green monkey and the rabbit cells contain the initial deamidation isozymes $-1 / 1^{\prime}$ and $-1^{\prime} / 1^{\prime}$, and green monkey hemolysates exhibit a TPI isozyme pattern identical to that of human erythrocytes (Figs. 3 and 6; Turner et al., 1984). Also, the rabbit enzyme has been shown to have the labile aspargines in positions 15 and 71 , as does the human enzyme (Yuan et al., 1981). The nonidentity of TPI-1/2 and the closely migrating 1 " $/ 1^{\prime \prime}$ deamidation isozyme is supported by a comparison of placental and muscle, or erythrocyte extracts. The deamidation isozymes, $-1 / 1^{\prime}$ through $-1^{\prime \prime} / 1^{\prime \prime}$, have identical rates of migration in both tissue extracts, however, TPI-1/2 clearly has a faster rate of migration than TPI-1"/1". Further, Gracy and co-workers have demonstrated the subunit structure of TPI-1"/ 1 " to be a homodimer of doubly deamidated subunits (Yuan et al., 1981), while our evidence suggests a heterodimeric structure for TPI-1/2 (Decker and Mohrenweiser, 1983).

In keeping with the conclusion that a single structural gene encodes these isozymes, we have previously suggested that the cell division-associated TPI-2 subunit is a modified form of the constitutive TPI- 1 subunit. The restriction of TPI-2 to hominoids implies specificity of the modification event. This is especially compelling in view of the conservative nature of the TPI structure. This phylogenetic restriction reinforces the genetic basis for the proposed modification and suggests a recently evolved regulatory mechanism which may represent an alternative strategy to gene duplication for evolution of protein structure and function. Further work is in progress which should 


\author{
elucidate the regulatory and structural basis for this cell cycle-associated \\ isozyme.
}

\title{
REFERENCES
}

Asakawa, J., and Mohrenweiser, H. W. (1982). Characterization of two new electrophoretic variants of human triosephosphate isomerase: Stability, kinetic and immunological properties. Biochem. Genet. 20:59.

Banner, D. W., Bloomer, A. C., Petsko, G. A., Phillips, D. C., Pogson, C. I., Wilson, I. A., Corran, P. H., Furth, A. J., Milman, J. D., Offord, R. E., Priddle, J. D., and Waley, S. G. (1975). Structure of chicken muscle triosephosphate isomerase determined crystallographically at 2.5 A resolution using amino acid sequence data. Nature Lond. 255:609.

Capetanaki, Y. G., Ngai, J., Flytzanes, C. N., and Lazarides, E. (1983). Tissue specific expression of two mRNA species transcribed from a single vimentin gene. Cell 35:411.

Choi, K. W., and Bloom, A. D. (1970). Cloning human lymphocytes in vitro. Nature 227:171.

Corran, P. H., and Waley, S. G. (1975). The amino acid sequence of rabbit muscle triosephosphate isomerase. Biochem. $J$. 145:335.

Crabtree, G. R., and Kant, J. A. (1982). Organization of the rat $\gamma$ fibrinogen gene: Alternative mRNA splice patterns produce the $\gamma \mathrm{A}$ and $\gamma \mathrm{B}\left(\gamma^{\prime}\right)$ chains of fibrinogen. Cell 31:159.

Decker, R. S., and Mohrenweiser, H. W. (1981). Origin of the triosephosphate isomerase isozymes in humans: Genetic evidence for the expression of a single structural locus. Am.J. Hum. Genet. 33:683.

Decker, R. S., and Mohrenweiser, H. W. (1983). Initial structural characterization of a thermolabile, cell-division associated isozyme of hominoid triosephosphate isomerase. Fed. Proc, 42:1914.

Dreyfus, J. C., Kahn, A., and Schapira, F. (1978). Posttranslation modifications of enzymes. Curr. Top. Cell. Regul. 14:243.

Early, P., Huang, H., Davis, M., Calame, K., and Hood, L. (1980). An immunoglobulin heavy chain variable region gene is generated from three segments of DNA: $\mathrm{V}_{\mathrm{H}}, \mathrm{D}$ and $\mathrm{J}_{\mathrm{H}} \cdot$ Cell 19:981.

Gracy, R. W., and Yuan, P. M. (1980). Spontaneous deamidation of two asparagines within the subunit contact sites of human triosephosphate isomerase. Fed. Proc, 39:1960.

Goldstein, D. J., Rogers, C., and Harris, H. (1982). Evolution of alkaline phosphatases in primates. Proc. Natl. Acad. Sci. USA 79:879.

Harris, H. (1980). The Principles of Human Biochemical Genetics, Elsevier/North-Holland, New York.

Harris, H., Hopkinson, D. A., and Robson, E. B. (1974). The incidence of rare alleles determining electrophoretic variants: Data on 43 enzyme loci in man. Ann. Hum. Genet. (Lond.) 37:237.

Kester, M. V., and Gracy, R. W. (1975). Alteration of human lymphocyte triosephosphate isomerase during blastogenesis. Biochem. Biophys. Res. Comm. 65:1270.

Kester, M. V., Jacobson, E. L., and Gracy, R. W. (1977). The synthesis of a labile triosephosphate isomerase in human lymphocytes and fibroblasts. Arch. Biochem. Biophys. 180:562.

Levin, M. J., Daegelen, D., Meienhofer, M. C., Dreyfus, J.-C., and Kahn, A. (1982). Two different species of messenger RNA's specify synthesis of $M_{1}$ and $M_{2}$ pyruvate kinase subunits. Biochim. Biophys. Acta 699:77.

Long, M. W., Hanash, S., and Krzesicki, R. (1985). Human platelet proteins: Characterization by high resolution two-dimensional electrophoresis and silver staining. Biochim. Biophys. Acta (in press).

Marie, J., Simon, M.-P., Dreyfus, J.-C., and Kahn, A. (1981). One gene, but two messenger RNAs encode liver $L$ and red cell L' pyruvate kinase subunits. Nature 292:70.

Marie, J., Simon, M.-P., and Kahn, A. (1982). Cotranslation of $L$ and L' pyruvate kinase messenger RNAs from human fetal liver. Biochim. Biophys. Acta 692:340.

Market, C. L. (1974). Biology of Isozymes. In Markert, C. L. (ed.), Isozymes I. Molecular Structure, Academic Press, New York, p. 1. 
Nabeshima, Y., Fujii-Kuriyama, Y., Muramatsu, M., and Ogata, K. (1984). Alternative transcription and two modes of splicing result in two myosin light chains from one gene. Nature 308:333.

Nasmyth, K. A., and Tatchell, K. (1980). The structure of transposable yeast mating type loci. Cell 19:753.

Neel, J. V., Mohrenweiser, H. W., and Meisler, M. M. (1980a). Rate of spontaneous mutation at human loci encoding protein structure. Proc. Natl. Acad. Sci. USA. 77:6037.

Neel, J. V., Satoh, C., Hamilton, H. B., Otake, M., Goriki, K., Kageoka, T., Fujita, M., Neriishi, S., and Asakawa, J. (1980b). A search for mutations affecting protein structure in children of a tomic bomb survivors: Preliminary report. Proc. Natl. Acad. Sci. USA 77:4221.

Oray, B., Lu, H. S., Talent, J. M., and Gracy, R. W. (1983). High sensitivity structural studies on human triosephosphate isomerase. Fed. Proc. 42:1764.

Peters, J., Hopkinson, D. A., and Harris, H. (1973). Genetic and non-genetic variation of triose phosphate isomerase isozymes in human tissues. Ann. Hum. Genet. Lond. 36:297.

Putnam, S. J., Coulson, A. F. W., Farley, I. R. T., Riddleston, B., and Knowles, J. R. (1972). Specificity and kinetics of triosephosphate isomerase from chicken muscle. Biochem. $J$. 129:301.

Rogers, P. A., Brenton, D. P., and Hopkinson, D. A. (1980). Changes in the activity and isozyme patterns of glycolytic enzymes during stimulation of normal human lymphocytes with phytohaemagglutin. Ann. Hum. Genet. (Lond.) 43:213.

Rubinson, H., Vodovar, M. C., Meienhofer, M. C., and Dreyfus, J. C. (1971). A unique electrophoretic pattern of TPI in human cultured fibroblasts. FEBS Lett. 13:290.

Rubinson, H., Meienhofer, M. C., and Dreyfus, J. C. (1973). A new isozyme of triosephosphate isomerase specific to hominoids. J. Mol. Evol. 2:243.

Saheki, S., Saheki, K., and Tanaka, T. (1982a). Peptide structures of pyruvate kinase isozymes I. Comparison of the four pyruvate kinase isozymes of the rat. Biochim. Biophys. Acta 704:484.

Saheki, S., Saheki, K., Tanaka, T., and Tanaka, T. (1982b). Peptide structures of pyruvate kinase isozymes II. Origins of types $\mathbf{M}_{1}$ and $\mathbf{M}_{2}$ isozymes suggested from species variation in their peptide maps. Biochim. Biophys. Acta 704:494.

Schwarzbauer, J. E., Tamkum, J. W., Lemischka, I. R., and Hynes, R. O. (1983). Three different fibronectin mRNAs arise by alternate splicing within the coding region. Cell 35:421.

Scopes, R. K. (1968). Methods for starch gel electrophoresis of sacoplasmic proteins: An investigation of the relative mobilities of the glycolytic enzymes from the muscles of a variety of species. Biochem. J. 107:139.

Snapka, R. M., Sawyer, T. H., Barton, R. A., and Gracy, R. W. (1974). Comparison of the electrophoretic properties of triosephosphate isomerases of various tissue and species. Comp. Biochem. Physiol. 49B:733.

Turner, T. R., Wade, P. T., and Mohrenweiser, H. W. (1984). Variation in erythrocyte enzyme activity among primate species. Comp. Biochem. Physiol. 77B:541.

Wold, F. (1981). In vivo chemical modification of proteins. Annu. Rev. Biochem. 50:783.

Yamamoto, N., and zurHansen, H. (1979). Tumor promoter TPA enhances transformation of human leukocytes by Epstein-Barr virus. Nature 280:244.

Young, R. A., Hagenbuchle, O., and Schibler, U. (1981). A single mouse amylase gene specifies two different tissue-specific mRNAs. Cell 23:451.

Yuan, P. M., Dewan, R. N., Zaun, M., Thompson, R. E., and Gracy, R. W. (1979). Isolation and characterization of triosephosphate isomerase isozymes from human placenta. Arch. Biochem. Biophys. 198:42.

Yuan, P. M., Talent, J. M., and Gracy, R. W. (1981). A tentative elucidation of the sequence of human triosephosphate isomerase by homology peptide mapping. Biochim. Biophys. Acta 671:211. 